\title{
Protein Synthesis within Neuronal Growth Cones
}

\author{
Lauren Davis, Ping Dou, Marcia DeWit, and Stanley B. Kater \\ The Program in Neuronal Growth and Development and the Department of Anatomy and Neurobiology, Colorado State \\ University, Fort Collins, Colorado 80523
}

\begin{abstract}
This study investigates the capacity of neuronal growth cones to synthesize protein locally and independently of their cell body. Isolated growth cones were prepared from cultures of neurons from the snail Helisoma by transecting neurites proximal to the growth cone. The capacity for protein synthesis was tested by radiolabeling cultures with ${ }^{3} \mathrm{H}$-leucine and analyzing the resultant autoradiograms. Isolated growth cones displayed incorporation of ${ }^{3} \mathrm{H}$-leucine that was inhibited by treatment with the protein synthesis inhibitors anisomycin and pactamycin, indicating that ribosomal-dependent translation occurs in growth cones. Ultrastructural analyses of growth cones demonstrated the presence of polyribosomes, the machinery for protein synthesis. The density of polyribosomes varied between growth cones, even between different growth cones on the same neuron, suggesting that growth cones express a range of protein synthetic capabilities. That different types of growth cones possess differing capabilities for protein synthesis is suggested in autoradiograms of ${ }^{3} \mathrm{H}$-leucine incorporation by the growth cones of axonal and nonaxonal neurites; incorporation was radically reduced in axonal growth cones in comparison with non-axonal growth cones. Finally, growth cones that were isolated for $2 \mathrm{~d}$ prior to radiolabeling incorporate ${ }^{3} \mathrm{H}$-leucine in a eukaryotic ribosomal-dependent manner, suggesting that the capacity for translation is long-lived in growth cones. Taken together, these studies reveal a capacity for protein synthesis confined totally to the neuronal growth cone proper. The synthesis of proteins in growth cones could afford a mechanism for the alteration of growth cone structure or function. This is in accord with the view that growth cones participate autonomously, to at least some extent, in the processes of synaptogenesis and the construction of neuronal architecture.
\end{abstract}

Neuronal growth cones, at the tips of growing neurites, are specialized to explore their surroundings and ultimately to establish synaptic contacts. There are often large distances between growth cones and their cell bodies, suggesting that growth cones may not rely exclusively on information from the cell body but may themselves contain the machinery necessary to formulate a re-

\footnotetext{
Received Apr. 16, 1992; revised June 29, 1992; accepted July 6, 1992.

We thank Dennis Giddings for excellent technical help. We also thank Drs. Jim Bamburg, Vincent Rehder, Mark Wright, and Roger Davenport for helpful comments on the manuscript. This work was supported by NS24683 to S.B.K. and NIH Postdoctoral Fellowship NS08445 to L.D.

Correspondence should be addressed to Lauren Davis, Department of Anatomy and Neurobiology, Colorado State University, Fort Collins, CO 80523

Copyright (C) 1992 Society for Neuroscience 0270-6474/92/124867-11\$05.00/0
}

sponse to a given stimulus (for a review, see Davis et al., 1991). Furthermore, growth concs on the samc ncuron may encounter different environments. The capability of growth cones to respond to signals in their local environment could be facilitated if they are capable of autonomous activities.

The clearest demonstration that growth cones do contain at least some of the machinery necessary for autonomous activities comes from observations of the long-term survival of experimentally isolated growth cones. In this preparation, growth cones are completely isolated by the transection of their neurites, thus severing all metabolic and physiological communication with the cell body. Previous studies have demonstrated that isolated growth cones can survive for periods ranging up to several hours (Shaw and Bray, 1977) or days (Haydon et al., 1984; Guthrie et al., 1989).

The hypothesis that growth cones are capable of autonomous activities is made even more compelling by findings that growth concs remain physiologically viable after isolation, thus indicating that the machinery necessary for many growth cone activities resides within the growth cone itself. For example, growth cones of the snail Helisoma trivolvis remain motile, maintain normal resting potentials, and generate action potentials for at least $3 \mathrm{~d}$ following transection (Guthrie et al., 1989). The cellular substrate underlying calcium homeostasis appears to be intrinsic to the growth cone as well; isolated growth cones that are challenged with alterations in calcium influx are able to restore resting levels of $\left[\mathrm{Ca}^{2+}\right]_{i}$ similar to attached growth cones (Rehder et al., 1991). The independent capacity of growth cones for behavioral activities was dramatically illustrated by Haydon et al. (1984), who demonstrated that isolated growth cones reversibly respond to the application of 5-HT by the retraction of filopodia and lamellopodia in a manner similar to that of intact growth cones. The physiological viability and the ability of isolated growth cones to respond to environmental cues are clear indications of autonomous capabilities.

Protein synthesis accomplished locally within a growth cone would enable rapid and specific changes in a growth cone's cellular machinery. The capability for protein synthesis within growth cones would greatly enhance the potential for independent growth cone-environment interactions. There are no previous studies demonstrating the capacity for protein synthesis within growth cones. Thus, in this study, we directly test the hypothesis that protein synthesis can occur locally within growth cones. The results demonstrate that isolated growth cones of cultured neurons from the snail Helisoma can incorporate ${ }^{3} \mathrm{H}$ leucine into protein by a mechanism that is sensitive to inhibitors of ribosomal protein synthesis in eukaryotic systems. A recent study indicates that protein synthesis occurs in isolated hippocampal dendrites (Torre and Steward, 1992), suggesting 
that proteins may be synthesized locally in other neurons and in different neuronal regions as well.

The present study employs individually cultured nerve cells from the snail Helisoma. Many of these neurons can be dissociated and grown in culture, where they display robust, large growth cones that are ideal for isolation experiments. In addition, some of these neurons have been identified, and their electrophysiological and structural properties have been previously characterized (see Kater, 1974; Haydon et al., 1985; Guthrie et al., 1989). Portions of this article focus on observations of identified buccal ganglion neurons B5 and B19. These neurons have distinctly different characteristic morphologies (Haydon et al., 1985), respond differently to the application of certain neurotransmitters (Haydon et al., 1987; McCobb et al., 1988a,b), choosc different synaptic partncrs (Zoran ct al., 1990), and exhibit different levels of competence at regulating calcium homeostasis (Mills et al., 1989). In addition, the growth cones of neurons B5 and B19 ultrastructurally and physiologically resemble their respective parent neurons and, of course, differ from each other (Guthrie et al., 1989). The present study indicates that protein synthesis occurs in growth cones of both B5 and B19 neurons, as well as in unidentified neurons, suggesting that protein synthesis occurs in the growth cones of many different types of neurons.

Some of the results in this article have been summarized elsewhere (Davis and Kater, 1990; Davis et al., 1991).

\section{Materials and Methods}

Neuronal cell culture. Adult snails of Helisoma trivolvis (albino) with shell diameters of $15-18 \mathrm{~mm}$ were maintained as previously described (Haydon et al., 1985; Kater and Mattson, 1988). The dissection and culture media consisted of 50\% Leibowitz L-15 modified for Helisoma (HL-15) as described in detail in Wong et al. (1981) and Haydon et al. (1985). For dissections, buccal ganglia were removed and incubated for $35 \mathrm{~min}$ in HL-15 containing $0.1 \%$ trypsin (type III S, Sigma), followed by $10 \mathrm{~min}$ incubation in HL-15 containing $0.1 \%$ Trypsin inhibitor (Sigma).

Ganglia were pinned dorsal side up on Sylgard pads, and neurons were visualized using a dissecting microscope. Neurons were individually removed by first making an incision in the ganglionic sheath dorsolateral to the neuronal somata and then gently pulling the neuron into a micropipette (50-100 $\mu \mathrm{m}$ tip diameter). Isolated neurons were plated onto polylysine-coated glass coverslips and incubated in HL-15 that had been conditioned with Helisoma brains (Wong et al., 1981, 1984). The coverslips were equipped with plastic rings made from Tygon tubing (inner diameter, 3/16 inch; height, approximately $1.5 \mathrm{~mm}$ ) attached using melted beeswax. The plastic rings enhanced neuronal survival between the many changes of solution during the experiment by maintaining the level of fluid over the neurons. Cultures were incubated in a dark, humidified, room temperature environment for 18-20 hr after plating in order to obtain many large-sized growth cones.

Preparation of isolated growth cones. The morning following plating, neurites were transected to yield growth cones that were completely isolated from the cell body. Using a micromanipulator-controlled glass micropipette that had been pulled to a fine tip ( $<1 \mu \mathrm{m}$ tip), neurites were transected proximal to the growth cone while observed using a microscope and phase-contrast illumination. Following the isolation of growth cones, cultures were maintained in a humidified environment for 2-8 $\mathrm{hr}$ prior to radiolabeling.

Some experiments used long-term isolated growth cones. For these preparations, neurites were severed such that the growth cones and a small amount of their distal neurites were left on the culture substrate. The cell bodies were removed from the culture dish in order to abolish the possibility of new outgrowth from the cell body obscuring the isolated growth cones. Cultures of long-term isolated growth cones were maintained for 1 or $2 \mathrm{~d}$ prior to radiolabeling.

In one study, we examined the ability of growth cones isolated from axonal neurites to perform protein synthesis as reflected by the incorporation of ${ }^{3} \mathrm{H}$-leucine. For this study, axonal growth cones were isolated from the cell body shortly after they attached to the substrate (within $5 \mathrm{hr}$ after plating); cultures were then maintained overnight. Radiolabeling was performed the following day, when axonal growth cones were more securely adhered to the substrate and nonaxonal growth cones had appeared. For purposes of comparison with the long-term (overnight) isolated axonal growth cones, nonaxonal growth cones in other cultures were isolated the day prior to radiolabeling.

Radiolabeling and autoradiographic procedures. For radiolabeling, cultures were transferred into leucine-free medium and incubated for $30 \mathrm{~min}$. Cultures were then transferred into medium containing ${ }^{3} \mathrm{H}-4,5$ L-leucine (150 $\mu \mathrm{l}^{3} \mathrm{H}$-leucine $/ 1.2 \mathrm{ml}$ medium) and labeled for $30 \mathrm{~min}$. For those experiments in which protein synthesis was inhibited, cultures were incubated for $30 \mathrm{~min}$ prior to radiolabeling with either anisomycin (20 $\mathrm{mm}$ ) or pactamycin $(25 \mathrm{~mm})$ to inhibit protein synthesis. Cultures were then radiolabeled in the presence of the same protein synthesis inhibitor. Following radiolabeling, cultures were rapidly washed twice with saline containing an excess of unlabeled leucine $\left(10^{-4} \mathrm{M}\right)$, and fixed using paraformaldehyde $(4 \%)$ to remove the unbound ${ }^{3} \mathrm{H}$-leucine. $\mathrm{Cul}-$ tures were dehydrated using graded ethanols, and the plastic rings were removed using xylene. Following two washes in $100 \%$ ethanol, cultures were air dried and mounted on glass microscope slides.

The following morning, the microscope slides were dipped in Kodak NTB2 emulsion $\left(42^{\circ} \mathrm{C}\right)$ to coat the coverslips, dried for at least $3 \mathrm{hr}$, packed with desiccant in light-tight boxes, and stored at $4^{\circ} \mathrm{C}$ for 2 weeks. Autoradiograms were developed using Kodak D-19 $\left(15^{\circ} \mathrm{C}\right)$ for $3 \mathrm{~min}$ and fixed for $4 \mathrm{~min}$ using Kodak fixer. Finally, autoradiograms were coverslipped using Kaiser's glycerol mountant for microscopic observation and data analysis.

In some experiments, ribonuclease A was used to destroy the total cytoplasmic RNA. For these experiments, cultures were pulse labeled with ${ }^{3} \mathrm{H}$-leucine for $30 \mathrm{~min}$, and fixed and dehydrated as described above. Cultures then were permeabilized with absolute cthanol for 30 min, rehydrated, and then digested with ribonuclease A (Sigma R-5503; $100 \mu \mathrm{g} / \mathrm{ml}$ ) for $30 \mathrm{~min}$ at room temperature. Processing for autoradiography was as described above.

Cultures containing intact neurons only (see Fig. 1 below) were prepared as described above, except that radiolabeling was for $15 \mathrm{~min}$.

Data analysis. Growth cones, initially isolated prior to radiolabeling and processing, were relocated on the microscope slide using phase illumination, and the image was captured by a Dage-MTI model 70 camera (Newvicon) coupled to a Macintosh IIci computer (Data Translation frame grabber board). The same field viewed using dark-field illumination to visualize the silver grains was also captured. Both images were displayed and overlaid using the shareware program IMAGE 1.41, and the silver grains over each isolated growth cone were manually counted. The mean number of silver grains per growth cone in each condition was calculated. The Mann-Whitney $U$ test was used to compare statistically the mean number of silver grains across conditions. All results are given as mean \pm SEM.

To determine the background density of silver grains, templates of five randomly selected growth cones were placed over areas of the coverslip that were randomly selected by microscope stage coordinates. The silver grains that lay within the outline of the template were counted, and the mean background density was calculated.

Electron microscopy. Neurons were plated on polylysine-treated, carbon-coated coverslips. The following morning, a few growth cones were isolated on two cells, using the techniques described above. Approximately $2 \mathrm{hr}$ later, cultures were fixed for $30 \mathrm{~min}$ in $1.5 \%$ glutaraldehyde in $\mathrm{HL}-15$ at room temperature and postfixed in $\mathrm{OsO}_{4}(1 \%)$ in $\mathrm{HL}-15$ for $15 \mathrm{~min}$ at $4^{\circ} \mathrm{C}$. Cultures were stained en bloc in $2 \%$ uranyl acetate and flat embedded in Epon Araldite resin. Following polymerization, a razor blade was used to separate the coverslip gently from the layer of embedded cells. Neurons were identified and cut from the resin layer, glued onto a blank resin block, cut into $400-500$ - $\AA$-thick ultrathin sections, and collected on Formvar-coated mesh or slot grids. Sections were stained with uranyl acetate and lead citrate and examined on a JEOL-2000 microscope.

One ultrathin section of each identified growth cone was selected for further analyses. Photographs of the entire growth cone profile on the section were taken and printed at a final magnification of 37,500 or 25,000 for quantitative analyses. Each photomicrograph was carefully scanned for the presence of polyribosomes, which were defined as clusters of at least four densely staining ribosomes; ribosomes were approximately $20-25 \mathrm{~nm}$ in diameter. The area of the growth cone was determined by scanning a low-magnification photomicrograph of the 

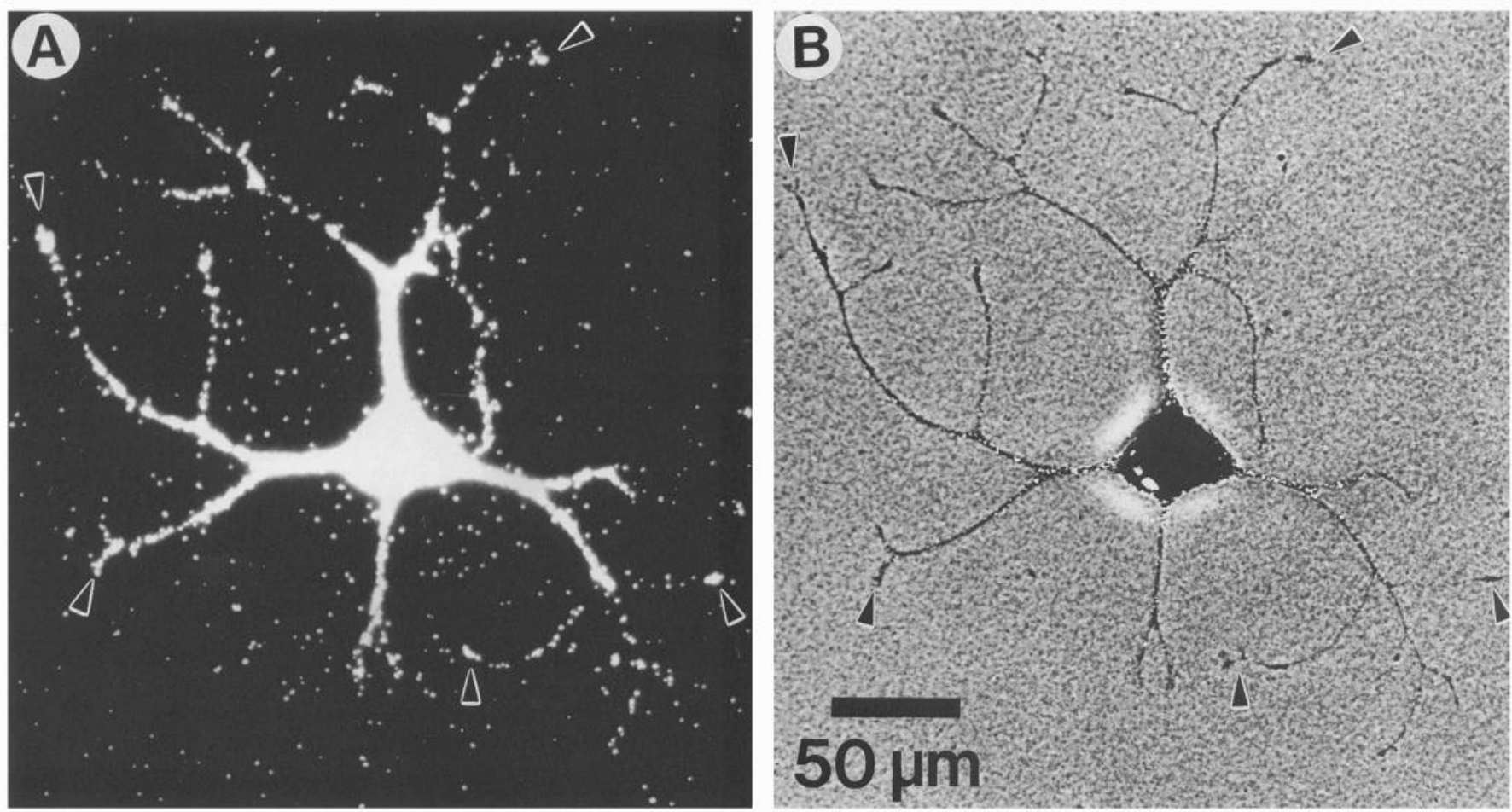

Figure 1. Incorporation of amino acids by Helisoma neurons. This neuron was radiolabeled with ${ }^{3} \mathrm{H}$-leucine for 15 min prior to fixation and processing for autoradiography. The neuron was photographed in dark-field illumination $(A)$ and phase-contrast illumination $(B)$. Silver grains, indicating the presence of radiolabeled protein, appear bright in the dark-field photomicrograph. A comparison of the dark-field and phase-contrast photomicrographs illustrates that silver grains are distributed over the complete extent of the cell. Note especially the heavy labeling over growth cones (arrowheads). Scale bar, $50 \mu \mathrm{m}$.

growth cone profile and measuring the perimeter of the profile with the aid of IMAGE 1.41. The density of polyribosomes in each growth cone was determined by calculating a ratio of the number of polyribosomes per $100 \mu \mathrm{m}^{2}$.

There was an exceptionally high density of polyribosomes and profiles that appeared to be free ribosomes in the growth cones of one B5 neuron. A different method of quantitation was used to determine the density of ribosomes in this neuron. A template circle representing an area of $0.05 \mu \mathrm{m}^{2}$ relative to the photographic magnification was copied 15 times onto an acetate sheet according to randomly preselected coordinates. The acetate sheet was overlaid onto each photograph of the growth cone, the total number of ribosomes [individual ribosomes that appeared to be part of a polyribosome cluster + ribosomes associated with rough endoplasmic reticulum (RER) + ribosomes that did not fall in either of these categories] that appeared within each circle was countedm and the mean number of ribosomes $/ 0.05 \mu \mathrm{m}^{2}$ was calculated. Similar analyses were also executed on a sample of 10 photomicrographs of the soma.

Chemicals. ${ }^{3} \mathrm{H}-4,5-\mathrm{L}-\mathrm{leucine}$ was purchased from New England $\mathrm{Nu}-$ clear (specific activity, 40-60 Ci/mmol). Leucine-free medium was Leibovitz L-15 specially prepared without L-leucine (GIBCO). Anisomycin was either a gift from Pfizer, Inc., or purchased from Sigma. Pactamycin was purchased from Aldrich $\mathrm{ABC}$.

\section{Results}

\section{Incorporation of exogenously administered ${ }^{3} \mathrm{H}$-amino acids}

Initially, whole neurons were radiolabeled for $15 \mathrm{~min}$ in ${ }^{3} \mathrm{H}-$ leucine to determine the distribution of recently synthesized protein throughout the cell. Autoradiographs reveal silver grains, indicating the presence of ${ }^{3} \mathrm{H}$-proteins, over the entire neuron including growth cones. Even though many of the growth cones can reach over $200 \mu \mathrm{m}$ from the cell body, a map of the full morphology of these cells is produced by the silver grains (see Fig. 1). Intracellular transport mechanisms are undoubtedly re- sponsible for the movement of many components between the cell body and growth cones. However, $15 \mathrm{~min}$ is rather short for the synthesis and transport of ${ }^{3} \mathrm{H}$-protein from the cell body into growth cones. This suggests the possibility that ${ }^{3} \mathrm{H}$-protein is synthesized locally in the growth cone.

The following experiments were designed to test directly for the possibility of protein synthesis within growth cones using a single modification in these procedures, namely, isolation of individual neuronal growth cones (see Fig. $2 A, B$ ). Isolated growth cones continue to elongate for several days following transection from the neurite (Fig. 2C,D). Such robust, isolated growth cones provide an opportunity to ask whether components of neuronal structure can, in the absence of a nucleus or other machinery associated with the cell body, incorporate amino acids.

Incorporation of ${ }^{3} \mathrm{H}$-amino acids into isolated growth cones. Cultures containing growth cones isolated from both identified (B5 and B19) and unidentified neurons were radiolabeled in ${ }^{3} \mathrm{H}-$ leucine for $30 \mathrm{~min}$. Autoradiographs of these cultures reveal dense radiolabeling over isolated growth cones (Fig. $3 A$ ). Quantitative analyses reveal that labeling is at least 15 times background (see Fig. 4). Because growth cones were isolated prior to labeling with ${ }^{3} \mathrm{H}$-leucine, radiolabeling in isolated growth cones indicates that incorporation is accomplished independently in the growth cone, and could not result from the transport of ${ }^{3} \mathrm{H}$-proteins synthesized in the cell body.

Demonstration of protein synthesis in isolated growth cones. The accumulation of radiolabel in isolated growth cones could result from a variety of reasons including the possibility that ${ }^{3} \mathrm{H}$-labeled proteins are newly synthesized in growth cones. To analyze whether radiolabeling represents the synthesis of radio- 

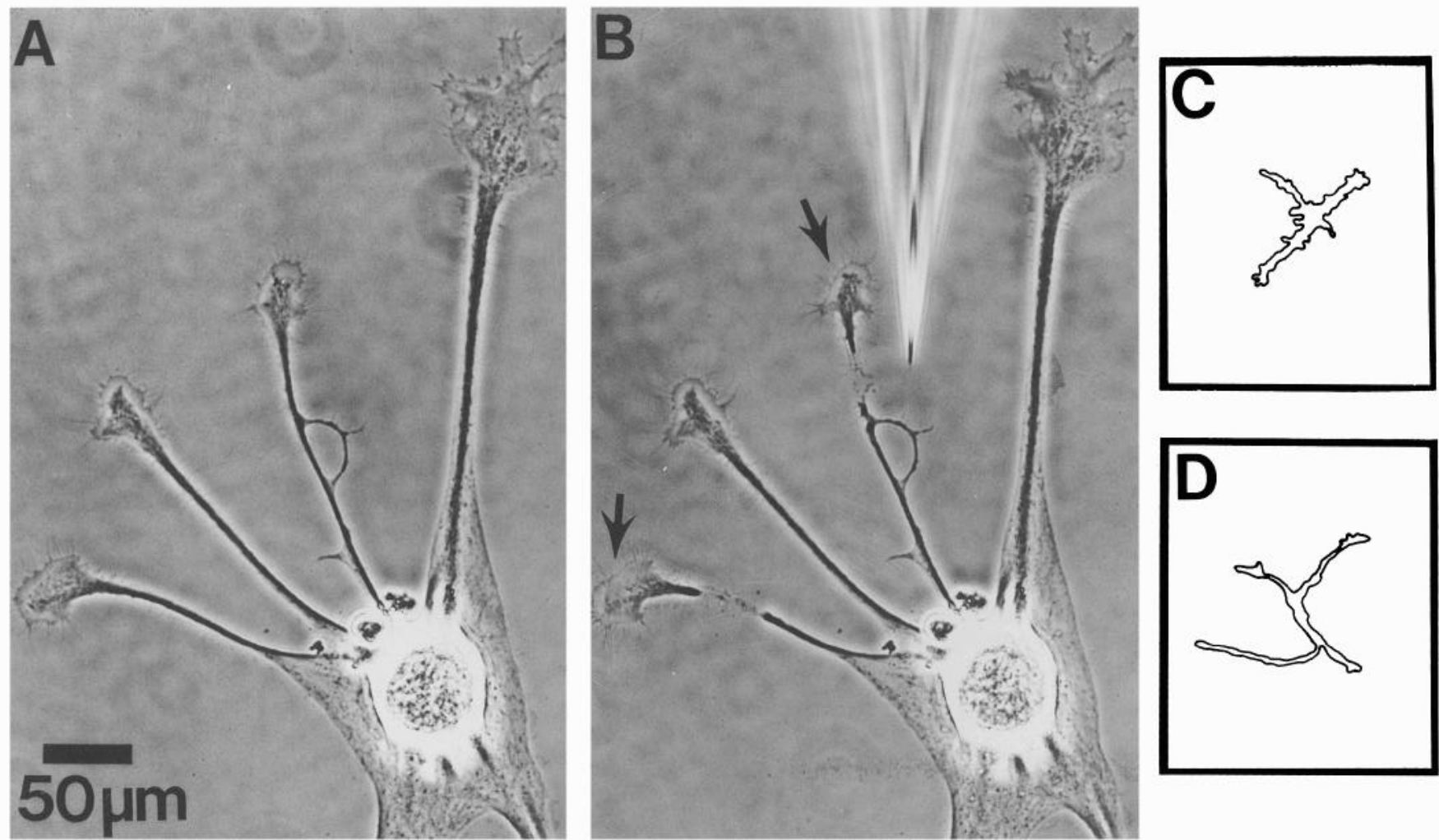

Figure 2. Growth cones survive in culture when isolated from the rest of the cell. $A$, Growth cones attached to the cell body (before isolation). $B$, It is possible, with a high degree of precision, to isolate individual growth cones from the parent neuron by cutting their neurites while leaving other growth cones still attached to the neuron. Growth cones are isolated by severing the neurite proximal to the growth cone using a micromanipulator controlled glass micropipette. Arrows point to isolated growth cones. Scale bar, $50 \mu \mathrm{m}$. Both $C$ and $D$ are schematic drawings that typify the morphology of long-term isolated growth cones; they were drawn as composites of several growth cones at each time interval. $C$ illustrates a growth cone $1 \mathrm{~d}$ after isolation. Notice that the growth cone no longer exhibits the typical rounded shape; processes have begun to extend and elongate from a central region. $D$ shows the appearance of a typical growth cone $2 \mathrm{~d}$ after isolation. Additional processes have emerged and continue to elongate.
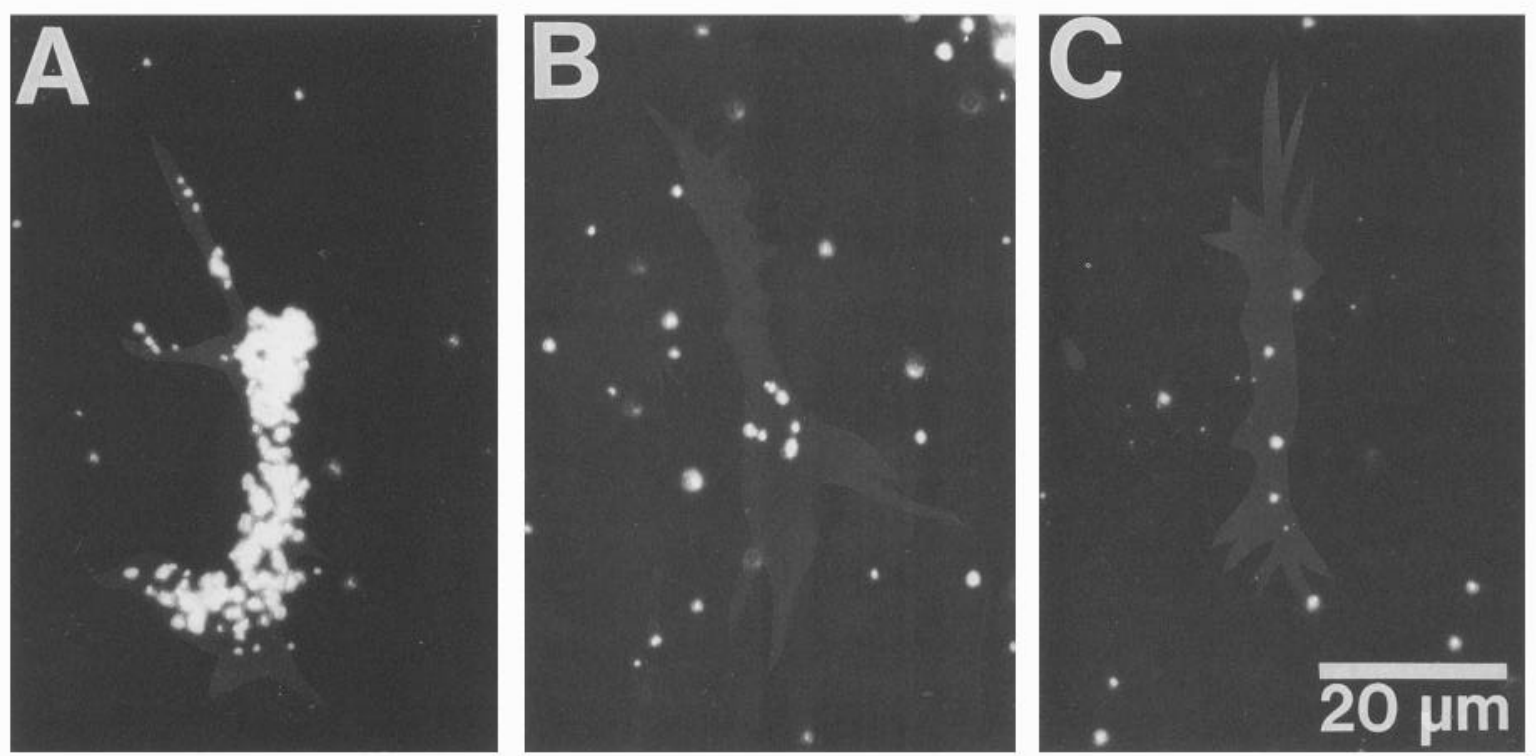

Figure 3. Protein synthesis occurs locally in isolated growth cones. Autoradiographs were prepared from cultures that were radiolabeled for 30 min. The area of the isolated growth cones (prepared from phase-contrast images) forms a light gray overlay over the dark-field photomicrographs. $A$, Isolated growth cones are heavily labeled. Labeling is greatly reduced in isolated growth cones in cultures that were treated with anisomycin $(B)$ or pactamycin $(C)$. Scale bar, $20 \mu \mathrm{m}$. 
labeled proteins, we employed pharmacological agents known to affect RNA translation. Anisomycin is an inhibitor of protein synthesis in eukaryotic cells and pactamycin is an inhibitor of protein synthesis in both prokaryotic (mitochondrial) and eukaryotic systems; both of these inhibitors previously have been shown to be effective in molluscan neurons (Schwartz et al., 1971; Barker et al., 1982; Wong et al., 1984). Radiolabeling will be decreased when cultures are pulse labeled in the presence of anisomycin if protein synthesis occurs via a ribosomal mechanism. There will be a greater decrease in radiolabeling in the presence of pactamycin since both prokaryotic and eukaryotic protein synthesis are inhibited.

Radiolabeling is greatly diminished over isolated growth cones (as well as over the rest of the neuron) when cultures are pretreated with either one of the inhibitors, and then radiolabeled for $30 \mathrm{~min}$ in the presence of the same inhibitor (see Fig. 3). In quantitative analyses of three replicate experiments, significant differences are observed between the growth cones that were not inhibited and either anisomycin- or pactamycin-treated preparations (Fig. 4). Labeling is also significantly lower in pactamycin-inhibited cultures than anisomycin preparations in experiments $1(p<0.001)$ and $3(p=0.01)$. It is important to note that although values of the basal incorporation vary in each of the three replicate experiments, radiolabeling is significantly reduced by at least $70 \%$ in cultures treated with anisomycin. Labeling in pactamycin cultures approximates background labeling (Fig. 4).

Neurons B5 and B19 are two of the most extensively characterized neurons from the buccal ganglion. To examine whether protein synthesis occurs in different types of neurons, several of our experiments have been performed on growth cones isolated from B5 and B19 neurons. Growth cones isolated from either of these types of neurons are labeled when incubated in the presence of ${ }^{3} \mathrm{H}$-leucine (B5 growth cones: basal incorporation $=33.7 \pm 6.8, N=9$; $\mathrm{B} 19$ growth cones: basal incorporation = $67.6 \pm 29.9, N=7)$. There is no significant difference in incorporation by the growth cones of neurons B5 and B19 ( $p=$ $0.4)$. Analyses of labeling in growth cones isolated from either of these identified neurons indicate that the number of silver grains is significantly reduced to a similar extent by protein synthesis inhibitors [B5 growth cones: anisomycin, $5.5 \pm 1.0$ $(N=11 ; p<0.0001$ compared to basal incorporation); pactamycin, $4.4 \pm 1.2(N=17 ; p<0.0001$ compared to basal incorporation); B19 growth cones: anisomycin, $6.2 \pm 1.8(N=$ $12 ; p<0.02$ compared to basal incorporation); pactamycin, 1.3 $\pm 0.5(N=13 ; p<0.0001$ compared to basal incorporation)].

Two alternative sources for the presence of radiolabel in isolated growth cones have been eliminated. In principle, radiolabel could arise from ${ }^{3} \mathrm{H}$-leucine that is bound to tRNA. This possibility was negated by experiments in which radiolabeled cultures were digested with ribonuclease A to destroy the cytoplasmic RNA. Quantitative analyses reveal that labeling over isolated growth cones is not significantly different in digested and nondigested cultures [basal incorporation, $9.9 \pm 2.4(N=$ 34); RNase, $12.9 \pm 3.4(N=33) ; p=0.27]$.

A final alternative is that proteins are synthesized in cell bodies, secreted into the medium, and then taken up by isolated growth cones. Isolated growth cones, however, are still heavily radiolabeled even when all parts of the neuron, except the isolated growth cones, are removed from the culture dish prior to radiolabeling (see Figs. $6 C, D, 7 A, B$ ). Thus, protein synthesis must occur locally within the growth cone itself.
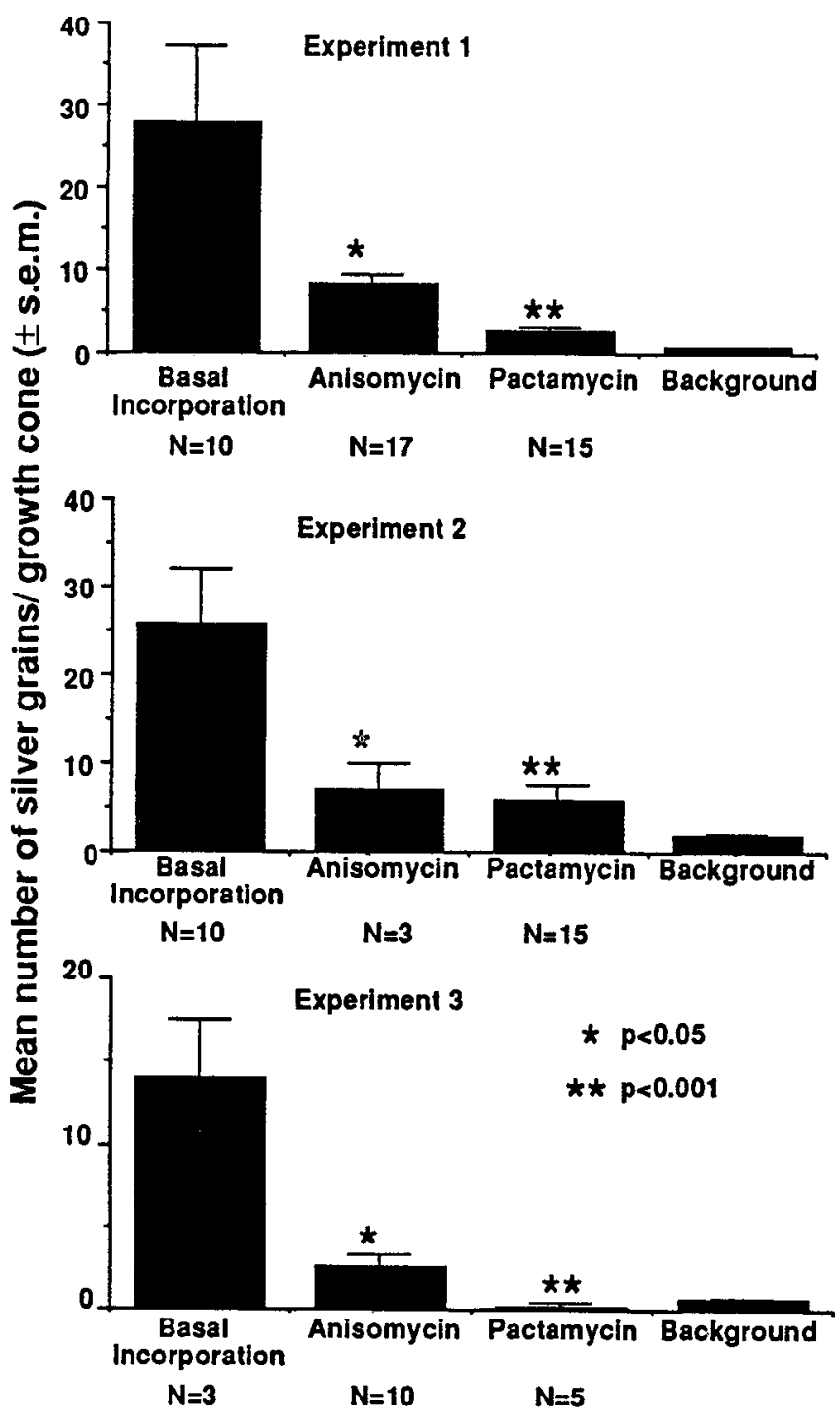

Figure 4. Graphic demonstration of the reduction in radiolabeling by protein synthcsis inhibitors. Graphs illustrate the results of three replicate experiments incorporating a total of 88 isolated growth cones from 42 cells. The number of isolated growth cones $(N)$ in each condition is listed below the bar. The background level of silver grains is indicated by the bar on the far right in each experiment.

Taken together, these data are consistent with the interpretation that mRNA translation-dependent protein synthesis occurs in isolated neuronal growth cones. In addition, there is apparently a relatively small amount of amino acid incorporation, likely of a mitochondrial origin.

\section{Localization of protein synthetic machinery in Helisoma growth cones}

Polyribosomes in growth cones. For protein synthesis to occur locally, the presence of protein synthetic machincry, that is, polyribosomes, in growth cones would be expected. Ultrastructural analyses reveal the presence of polyribosomes throughout the neuron. In general, the frequency of polyribosomes in growth cones is sparse, relative to the density in somata. The density of ribosomes in the most densely packed growth cone $(8.4 \pm$ 0.9 ribosomes $/ 0.05 \mu \mathrm{m}^{2} ; N=25$ ) is significantly lower than the 

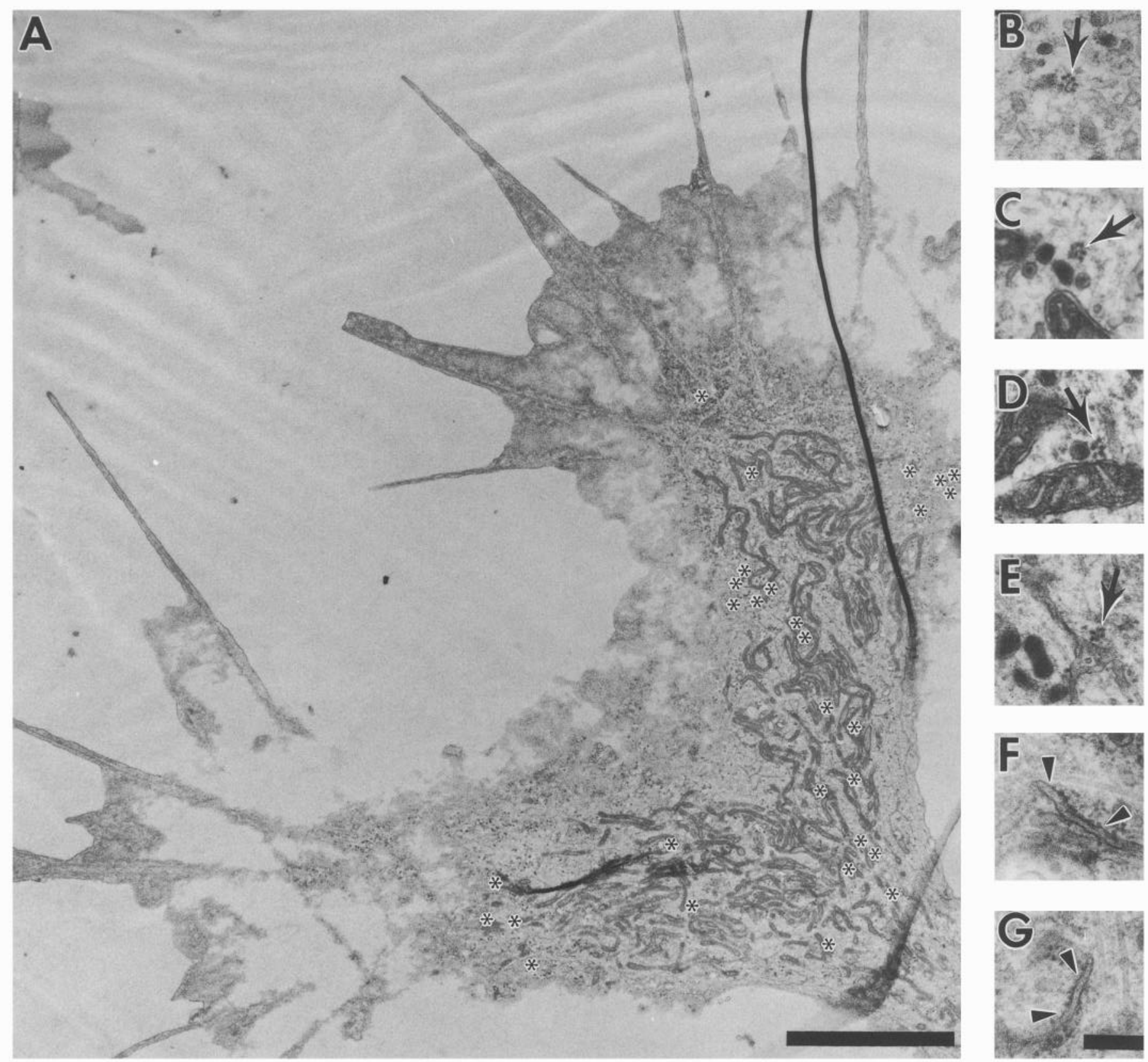

Figure 5. Ultrastructural evidence of protein synthetic machinery in growth cones. $A$ illustrates an electron photomicrograph of an ultrathin section of a growth cone (cell $7 \mathrm{~b}, \mathrm{gc} \# 2$ ). The position of the polyribosomes is indicated $(*) . B-D$, Representative examples of profiles of polyribosomes located in growth cones. $E$, Polyribosomes are frequently positioned near membranes in growth cones. Arrows point to profiles of polyribosomes. $F$ and $G$, Examples of profiles that appear to be RER located in growth cones. Arrowheads indicate areas of ribosome studded membrane. Scale bars: $A, 5 \mu \mathrm{m} ; B-G, 0.25 \mu \mathrm{m}$.

density of ribosomes in the soma of the same cell $(13.8 \pm 0.9$ ribosomes $\left./ 0.05 \mu \mathrm{m}^{2} ; N=133 ; p=0.004\right)$.

Polyribosomes apparently are more frequently located within the central rather than peripheral (lamellipodia and filopodia) region of the growth cone. Polyribosomes are occasionally, however, located in the lamellipodia, and even rarely within filopodia. Within the central region, there is no apparent pattern to the distribution of polyribosomes (see Fig. $5 A$ ). In addition, analyses of cross sections through growth cones indicate that polyribosome distribution appears random throughout the height of the growth cone. Isolated growth cones also contain polyri- bosomes (Table 1; see also following section), with the density of polyribosomes not significantly different from that in attached growth cones $(p>0.1)$. Similarly, there is no apparent pattern to the distribution of polyribosomes in isolated growth cones.

Occasionally, profiles of membranes studded with a few ribosomes are observed within both isolated and attached growth cones (Fig. $5 F, G$ ). These structures appear to be RER. The RER in growth cones is much less extensive and the membrane saccules appeared to be smaller and more rounded than the flat, extensive saccules in somata.

Variations in polyribosome density among different growth 
cones. The density of polyribosomes varies considerably between growth cones and does not appear to be related to the area of the growth cone $(r=0.148 ; F=0.225 ; p>0.05$; see Table 1). Furthermore, there is no significant difference in the density of polyribosomes in growth cones of neurons B5 and B19 $(p=0.08)$. In many cases, different growth cones on the same neuron have different densities of polyribosomes (see Table 1). Because these differences in the densities of polyribosomes may reflect a range of synthetic capabilities among the different growth cones of a single neuron, this observation was examined further.

In the growth cones of one B5 neuron there was an exceptionally high density of polyribosomes, as well as structures that appeared to be free ribosomes. Analyses of the growth cones of this B5 neuron were conducted to determine the density of ribosomes per $0.05 \mu \mathrm{m}^{2}$ area of growth cone. The density of ribosomes in four different attached growth cones ranges from $4.2 \pm 0.3$ to $8.4 \pm 0.9$ ribosomes $/ 0.05 \mu \mathrm{m}^{2}$. The density of ribosomes in a growth cone that had been isolated from this cell is $7.7 \pm 0.4$ ribosomes $/ 0.05 \mu \mathrm{m}^{2}$.

These data suggest that the capacity for protein synthesis may differ considerably in different growth cones. This possibility can be more clearly investigated by examining amino acid incorporation in two distinct populations of growth cones.

\section{Differential amino acid incorporation into different classes of growth cones}

Most neurons express two classes of neurites, axons and dendrites, which differ in function and morphology. For example, the capability for protein synthesis is expressed preferentially by dendrites (Steward and Levy, 1982; Davis et al., 1990; Torre and Steward, 1992). Although the identity of many invertebrate neurites, including Helisoma, has not been completely characterized, some differential aspects of invertebrate neurites and their growth cones have been described. Freshly isolated invertebrate neurons frequently maintain the residual axon found in the intact organism from which a growth cone-like structure rapidly emerges (Schacher and Proshansky, 1983; Haydon and Kater, 1987). In addition, growth cones also form at the tip of nonaxonal neurites that emerge directly from the cultured cell body. Axonal growth cones appear in many ways similar to nonaxonal growth cones except that axonal growth cones are typically several times larger, and usually take longer (approximately $8 \mathrm{hr}$ ) to emerge from the soma. Another difference is that axonal growth cones do not adhere to the substrate as securely as nonaxonal growth cones and often detach during the radiolabeling procedure. All of the analyses described in the other sections of this report have been accomplished using nonaxonal growth cones. In this section, we have also performed experiments on axonal growth cones. Although it was not possible to obtain a sample size of axonal growth cones suitable for statistical analyses in the studies in this section, the striking differences in labeling between axonal and nonaxonal growth cones have prompted the presentation of these observations.

Autoradiograms exhibit a paucity of silver grains over the two axonal growth cones that survived radiolabeling and processing (Fig. 6). Labeling is radically reduced over axonal growth cones in comparison with the labeling of growth cones isolated from nonaxonal neurites. There are no apparent decreases in labeling over axonal growth cones when cultures are radiolabeled in the presence of the protein synthesis inhibitors anisomycin and pactamycin.
Table 1. Ultrastructural analyses of polyribosomes in Helisoma growth cones

\begin{tabular}{lllllc} 
Cell & $\begin{array}{l}\text { Growth } \\
\text { cone } \\
\text { number }\end{array}$ & $\begin{array}{l}\text { Cell } \\
\text { type }\end{array}$ & $\begin{array}{l}\text { Isolated } \\
\text { (I) or } \\
\text { attached }\end{array}$ & $\begin{array}{l}\text { Area } \\
\left(\mu \mathrm{m}^{2}\right)\end{array}$ & $\begin{array}{l}\text { Polyribo- } \\
\text { somes/ } \\
100 \mu \mathrm{m}^{2}\end{array}$ \\
\hline la & $\# 2$ & B5 & A & 72.85 & 8.24 \\
la & $\# 3$ & B5 & A & 41.99 & 2.38 \\
la & $\# 4$ & B5 & A & 31.79 & 9.44 \\
4a & $\# 1$ & B5 & A & 156.04 & 9.61 \\
4a & $\# 2$ & B5 & A & 146.4 & 29.37 \\
7b & $\# 1$ & B19 & A & 233.29 & 13.29 \\
7b & $\# 2$ & B19 & A & 304.68 & 9.85 \\
7b & $\# 6$ & B19 & A & 224.1 & 10.71 \\
7b & $\# 7$ & B19 & A & 47.98 & 27.09 \\
6a & $\# 9$ & B19 & A & 29.56 & 20.30 \\
6a & $\# 10$ & B19 & A & 47.50 & 8.42 \\
6a & $\# 11$ & B19 & A & 32.64 & 24.51 \\
6a & $\# 1$ & B19 & I & 52.31 & 17.21 \\
6a & $\# 2$ & B19 & I & 23.62 & 25.4 \\
6a & $\# 3$ & B19 & I & 36.93 & 16.25 \\
6a & $\# 4$ & B19 & I & 15.98 & 31.29 \\
6a & $\# 5$ & B19 & I & 83.09 & 7.22 \\
6a & $\# 6$ & B19 & I & 29.31 & 30.71 \\
6a & $\# 7$ & B19 & I & 7.64 & 78.53 \\
6a & $\# 8$ & B19 & I & 14.29 & 7.00 \\
\hline
\end{tabular}

The density of polyribosomes (represented as polyribosomes/100 $\mu \mathrm{m}^{2}$ ) in each growth cone, as well as the area of the growth conc in the analyzed section, the cell type, and whether the growth cone was isolated or attached are listed.

\section{Longevity of protein synthetic capability in growth cones}

The preceding studies indicate that nonaxonal growth cones are radiolabeled even though they have been isolated from the cell body for $1 \mathrm{~d}$ prior to radiolabeling (see Fig. $6 C, D$ ). This raises the notion that the capacity for protein synthesis within growth cones is retained for long periods of time. To address this question, long-term isolated growth cones were prepared. These isolated growth cones were allowed to survive for $48 \mathrm{hr}$ before radiolabeling for $30 \mathrm{~min}$ with ${ }^{3} \mathrm{H}$-leucine. Long-term isolation of growth cones results in the elaboration of a rather unusual morphology (see Fig. 2). The morphology is typically characterized by long, very thin processes emanating from a small central portion. The morphology, however, is extremely variable in terms of the length and number of these fine processes, and the size of the central region.

Dense labeling is evident over the central portion of longterm isolated growth cones; the long processes are sparsely labeled (Fig. 7A,B). Labeling over long-term isolated growth cones appears less dense than in growth cones that were freshly isolated or those that had been isolated for $1 \mathrm{~d}$ prior to radiolabeling (compare Fig. $7 A, B$ with Figs. $3 A, 6 C, D$ ). Because of the extreme variability in the morphology of long-term isolated growth cones, however, we felt it was unrealistic to attempt a quantitative evaluation of labeling in these growth cones.

To determine whether labeling in long-term isolated growth cones reflects a capacity for protein synthesis, cultures were radiolabeled in the presence of anisomycin or pactamycin. Autoradiograms reveal a decrease in labeling in inhibited cultures of long-term isolated growth cones (see Fig. 7). The decrease in labeling is similar in relative density to the decrease in labeling 

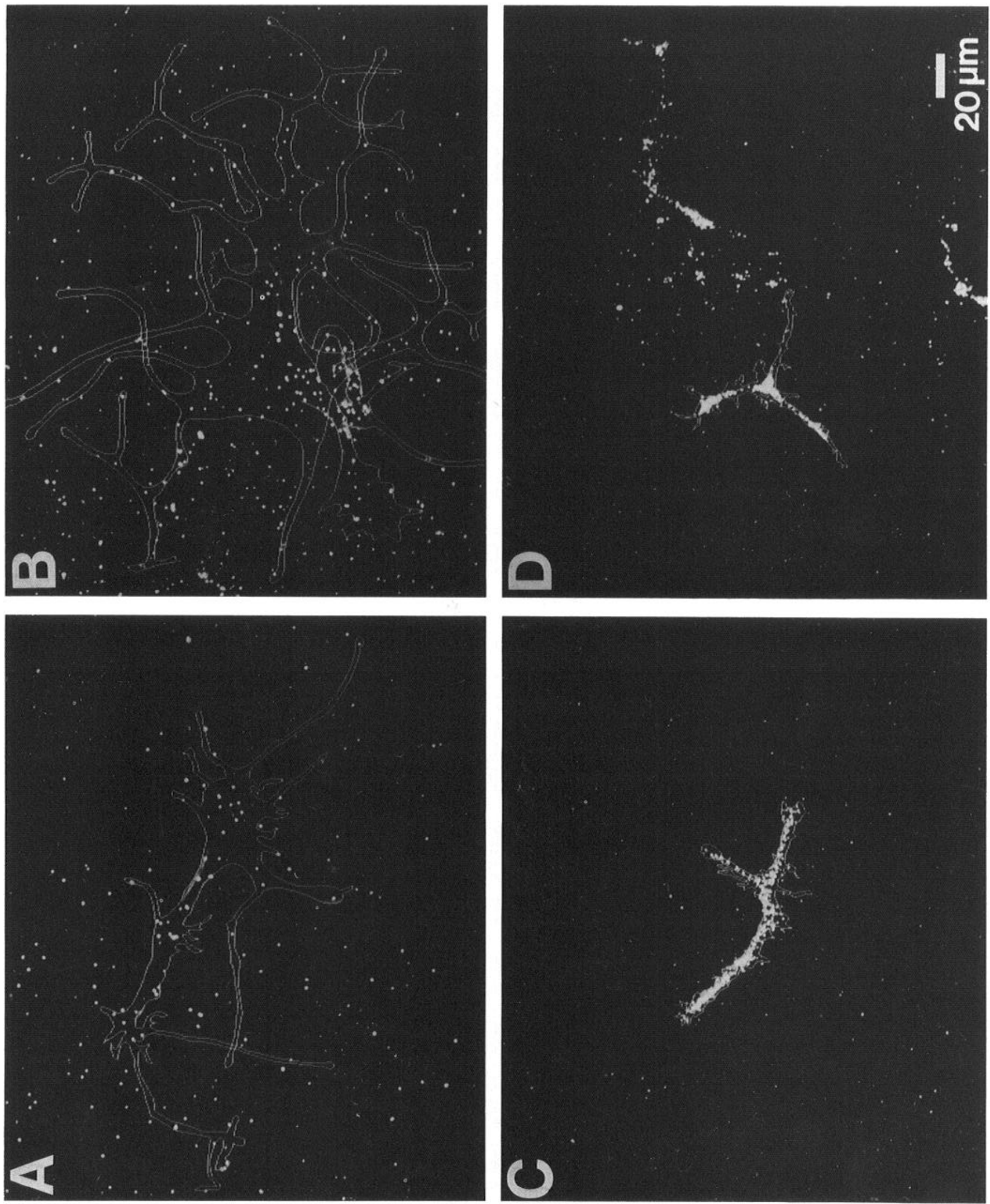

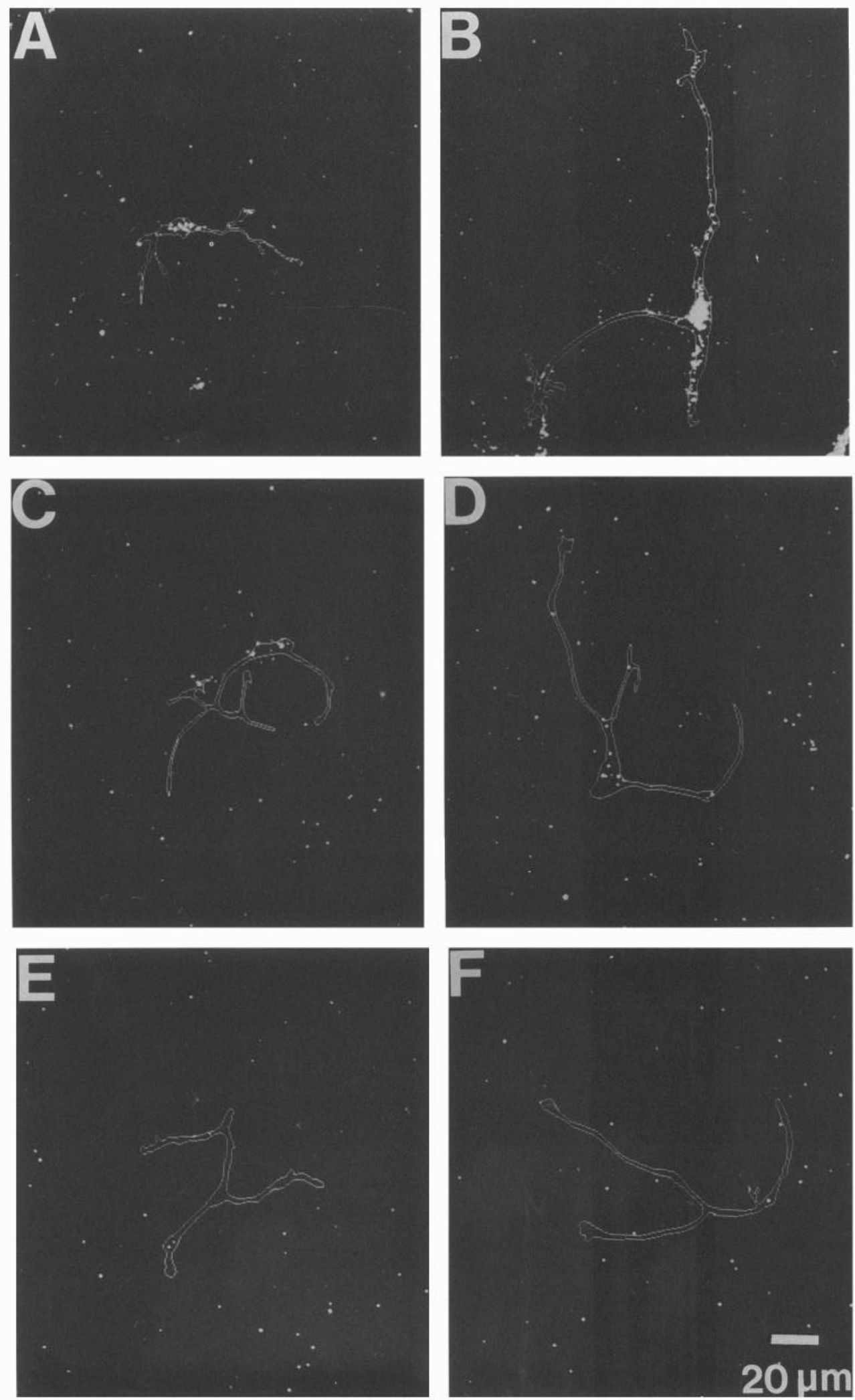

Figure 7. Protein synthesis in growth cones $2 \mathrm{~d}$ after isolation. Growth cones were isolated and then returned to culture for $2 \mathrm{~d}$ prior to radiolabeling for $30 \mathrm{~min}$ and processing for autoradiography. The outline of the isolated growth cones (prepared from phase-contrast images) is drawn in light gray over the dark-field photomicrographs. $A$ and $B$,) Long-term isolated growth cones are labeled, indicating the incorporation of ${ }^{3} \mathrm{H}$-amino acids. Labeling over longterm isolated growth cones is reduced when cultures are radiolabeled in the presence of anisomycin $(C, D)$, and pactamycin $(E, F)$, indicating that translation occurs in long-term isolated growth cones. Scale bar, $20 \mu \mathrm{m}$.

Figure 6. Protein synthesis locally in isolated axonal and nonaxonal growth cones. Axonal $(A, B)$ and nonaxonal $(C, D)$ growth cones were allowed to grow in culture for about $1 \mathrm{~d}$ following isolation, prior to radiolabeling for $30 \mathrm{~min}$ and processing for autoradiography. The outline of the isolated growth cones (prepared from phase-contrast images) is drawn in light gray over the dark-field photomicrographs. Axonal growth cones $(A, B)$ are lightly labeled in comparison with nonaxonal growth cones $(C, D)$. Scale bar, $20 \mu \mathrm{m}$. 
in freshly isolated growth cones that were inhibited with protein synthesis inhibitors.

\section{Discussion}

The demonstration of protein synthesis within growth cones is in accord with our contemporary view of this structurc, which recognizes a formidable role for growth cones in the formation of synapses and in the guidance of the construction of neuronal architecture. A preparation of cultured growth cones isolated from the rest of the cell has been used to demonstrate that amino acids are incorporated into protein by a ribosomal translation mechanism, and that polyribosomes, the machinery for accomplishing protein synthesis in eukaryotic systems, are located within growth cones. Furthermore, these results suggest that the factors involved in translation (such as mRNA) are stable in growth cones because the capacity for protein synthesis is retained for at least $48 \mathrm{hr}$ after isolation of growth cones.

The capacity for protein synthesis in neuronal growth cones is likely to be expressed in many different types of neurons. Indeed, in the present study, we report that polyribosomes are located in two identified neurons, and that ribosomal protein synthesis occurs in these cells as well as other unidentificd $\mathrm{Hel}$ isoma neurons. Moreover, the presence of polyribosomes has been reported in neuronal growth cones from rat cerebellum (Del Cerro and Snider, 1968), rabbit dorsal root (Tennyson, 1970), rat sympathetic ganglia (Bunge, 1973), mouse olfactory bulb (Hinds and Hinds, 1972), and chick spinal cord (Skoff and Hamburger, 1974), suggesting that growth cones of these cells, like those studied directly in the present investigation, have the capacity for protein synthesis.

\section{Longevity of the capability for protein synthesis}

The capacity for protein synthesis in growth cones exists for at least $2 \mathrm{~d}$ following isolation. These findings suggest that at least some of the mRNAs, as well as other factors involved in translation, are especially long-lived in Helisoma growth cones. The existence of stable mRNA in growth cones could indicate that certain classes of mRNA transcripts are delivered into growth cones. Although these studies do not reveal the identity of mRNAs in growth cones, the existence of RER, as well as polyribosomes that do not appear to be associated with membranes, suggests that various classes of mRNAs are present.

One possible reason for the long-lived capability of protein synthesis in growth cones may be that mRNA is positioned in growth cones until an appropriate cue for the initiation of translation is received. Another possibility is that transport of protein synthetic machinery from the cell body to the growth cones is sporadic or slow. Indeed, it has been reported that RNA is transported at a velocity of about $0.5 \mathrm{~mm} / \mathrm{d}$ in hippocampal dendrites, a rate that is characteristic of slow intracellular transport processes (Davis et al., 1987, 1990).

\section{Differential synthetic capacities in different growth cones}

These data suggest that there are multiple classes of growth cones with differing synthetic capacities. The ultrastructural data indicate that the density of polyribosomes varies between different growth cones, even among different growth cones on the same neuron. The differential synthetic capabilities are even more pronounced in the observations of axonal and nonaxonal growth cones. Taken together, these findings clearly suggest that structures found at the tips of extending neurites and displaying lamellipodial and filopodial structures do not have identical capacities. The fact that growth cones express a range of functional capabilities supports the hypothesis that growth cones function to some extent autonomously (Haydon et al., 1985; Davis et al., 1991).

That differing synthetic capacities are expressed in different growth cones may be related to the growing body of evidence indicating that protein synthesis occurs almost exclusively in the dendrites, rather than axons, of vertebrate neurons. For example, recently synthesized RNA is transported into dendrites via an energy-dependent mechanism (Davis et al., 1987, 1990), dendritic polyribosomes are selectively positioned beneath dendritic spines (Bodian, 1965; Palacios-Pru et al., 1981; Steward and Levy, 1982; Spacek, 1985), certain mRNAs are specifically localized in dendrites (Garner et al., 1988; Bruckenstein et al., 1990; Burgin et al., 1990; Kleiman et al., 1990), and it has recently been reported that amino acids are incorporated into proteins in isolated hippocampal dendrites (Torre and Steward, 1992). Interestingly, the capacity for ribosomal protein synthesis in the axons of other neurons has been demonstrated by several groups (Koenig and Adams, 1982; Jirikowski et al., 1990; Giuditta et al., 1991). In addition, there is evidence of a non-ribosomal posttranslational modification of proteins in squid giant axons by the addition of amino acids into proteins (Ingoglia et al., 1983). Thus, when viewed together, current evidence indicates that protein synthesis can be a highly compartmentalized process and that the specifics of amount, location, and the nature of the product can be quite different in different types of neurons.

\section{Significance and conclusions}

The capacity for protein synthesis within growth cones suggests it may be useful to reexamine our current view of the functional capacities of growth cones, and the relationship between growth cones and the rest of the cell. Part of the responsibility for accomplishing growth cone activities such as synapse formation and the construction of neuronal architecture may be delegated directly to growth cones themselves. Activation and regulation of synthesis within growth cones might be guided by interactions with the environment, or information from the cell body. Thus, each growth cone may achieve a "customized" identity with functional and structural capabilities that make the growth cone uniquely suited to its role in synaptogenesis and the formation of neuronal architecture.

\section{References}

Barker DL, Wong RG, Kater SB (1982) Separate factors produced by the CNS of the snail Helisoma stimulate neurite outgrowth and choline metabolism in cultured neurons. J Neurosci Res 8:419-432.

Bodian D (1965) A suggestive relationship of nerve cell RNA with specific synaptic sites. Proc Natl Acad Sci USA 53:418-425.

Bruckenstein DA, Lein PJ, Higgins D, Fremeau RT (1990) Distinct spatial localization of specific mRNAs in cultured sympathetic neurons. Neuron 10:809-819.

Bunge MB (1973) Fine structure of nerve fibers and growth cones of isolated sympathetic neurons in culture. $\mathrm{J}$ Cell Biol 56:713-735.

Burgin KE, Waxham MN, Rickling S, Westgate SA, Mobley WC, Kelly PT (1990) In situ hybridization histochemistry of $\mathrm{Ca}^{2+} /$ calmodulindependent protein kinase in developing rat brain. J Neurosci 10:17881798.

Davis L, Kater SB (1990) Local protein synthesis within isolated growth cones of cultured snail neurons. Soc Neurosci Abstr 16:961.

Davis L, Banker GA, Steward O (1987) Selective dendritic transport of RNA in hippocampal neurons in culture. Nature 330:477-479.

Davis L, Burger B, Banker GA, Steward O (1990) Dendritic transport: 
quantitative analysis of the time course of somatodendritic transport of recently synthesized RNA. J Neurosci 10:3056-3068.

Davis L, Rehder V, Kater SB (1991) Autonomous activities of the neuronal growth cone. In: The nerve growth cone (Letourneau $\mathrm{P}$, Kater SB, Macagno E, eds), pp 133-149. New York: Raven.

Del Cerro MP, Snider R (1968) Studies on the developing cerebellum: ultrastructure of the growth cones. J Comp Neurol 133:341-362.

Garner CC, Tucker RP, Matus A (1988) Selective localization of messenger RNA for cytoskeletal protein MAP2 in dendrites. Nature 336: 674-677.

Giuditta A, Menichini E, Perrone Capano C, Langella M, Martin R, Castigli E, Kaplan BB (1991) Active polysomes in the axoplasm of the squid giant axon. J Neurosci Res 28:18-28.

Guthrie PB, Lee RE, Kater SB (1989) A comparison of neuronal growth cone and cell body membrane: electrophysiological and ultrastructural properties. J Neurosci 9:3596-3605.

Haydon PG, Kater SB (1987) Novel roles for neurotransmitters: the regulation of neurite outgrowth, growth cone motility and synaptogenesis. In: Growth and plasticity of neural connections (Winlow W, McCrohan C, eds), pp 8-26. Manchester: Manchester UP.

Haydon PG, McCobb DP, Kater SB (1984) Serotonin selectively inhibits growth cone dynamics and synaptogenesis of specific identified neurons of Helisoma. Science 226:561-564.

Haydon PG, Cohan CS, McCobb DP, Miller HR, Kater SB (1985) Neuron-specific growth cone properties as seen in identified neurons of Helisoma. J Neurosci Res 13:135-147.

Haydon PG, McCobb DP, Kater SB (1987) The regulation of neurite outgrowth, growth cone motility, and electrical synaptogenesis by serotonin. J Neurobiol 18:197-215.

Hinds JW, Hinds PL (1972) Reconstruction of dendritic growth cones in neonatal mouse olfactory bulb. J Neurocytol 1:169-187.

Ingoglia NA, Giuditta A, Zanakis MF, Babigian A, Tasaki I, Chakraborty $\mathrm{G}$, Sturman JA (1983) Incorporation of ${ }^{3} \mathrm{H}$-amino acids into proteins in partially purified fraction of axoplasm: evidence for transfer RNA-mediated, post-translational protein modification in squid giant axons. J Neurosci 3:2463-2473.

Jirikowski GF, Paolo Sanna P, Bloom FE (1990) mRNA coding for oxytocin is present in axons of the hypothalamo-neurohypophysial tract. Proc Natl Acad Sci USA 87:7400-7404.

Kater SB (1974) Feeding in Helisoma trivolvis: the morphological and physiological bases of a fixed action pattern. Am Zool 14:1017-1036.

Kater SB, Mattson MP (1988) Extrinsic and intrinsic regulators of neurite outgrowth and synaptogenesis in isolated, identified Helisoma neurons in culture. In: Cell culture approaches to invertebrate neuroscience (Beadle D, Lees $\mathrm{G}$, Kater SB, eds), pp 1-31. London: Academic.

Kleiman R, Banker GA, Steward O (1990) Differential subcellular localization of particular mRNAs in hippocampal neurons in culture. Neuron 5:821-830.
Koenig E, Adams P (1982) Local protein synthesizing activity in axonal fields regenerating in vitro. J Neurochem 39:386-400.

McCobb DP, Cohan CS, Connor JA, Kater SB (1988a) Interactive effects of serotonin and acetylcholine on neurite elongation. Neuron $1: 377-385$

McCobb DP, Haydon PG, Kater SB (1988b) Dopamine and serotonin inhibition of neurite elongation of different identified neurons. J Neurosci Res 19:19-26.

Mills LR, Dou P, Kater SB (1989) Neuron specific differences in calcium homeostatic capacity. Soc Neurosci Abstr 15:438.

Palacios-Pru EL, Palacios L, Mendoza RV (1981) Synaptogenetic mechanisms during chick cerebellar cortex development. J Submicrosc Cytol 13:145-167.

Rehder V, Jensen JR, Dou P, Kater SB (1991) A comparison of calcium homenstasis in isolated and attached growth cones of the snail Helisoma. J Neurobiol 22:499-511.

Schacher S, Proshansky E (1983) Neurite regeneration by Aplysia neurons in dissociated cell culture: modulation by Aplysia hemolymph and the presence of the axon initial segment. J Neurosci 3:2403-2413.

Schwartz JH, Castellucci VF, Kandel ER (1971) Functioning of identified neurons and synapses in abdominal ganglion of Aplysia in absence of protein synthesis. J Neurophysiol 34:939-953.

Shaw G, Bray D (1977) Movement and extension of isolated growth cones. Exp Cell Res 104:55-62.

Skoff RP, Hamburger V (1974) Fine structure of dendritic and axonal growth cones in embryonic chick spinal cord. J Comp Neurol 153: 107-148.

Spacek J (1985) Three dimensional analysis of dendritic spines. II. Spine apparatus and other cytoplasmic components. Anat Embryol (Berl) 171:235-243.

Steward O, Levy WB (1982) Preferential localization of polyribosomes under the base of dendritic spines in granule cells of the dentatc gyrus. J Neurosci 2:284-291.

Tennyson VM (1970) The fine structure of the axon and growth cone of the dorsal root neuroblast of the rat embryo. J Cell Biol 44:62-78.

Torre ER, Steward O (1992) Demonstration of local protein synthesis within dendrites using a new cell culture system that permits the isolation of living axons and dendrites from their cell bodies. J Neurosci $12: 762-772$

Wong RG, Hadley RD, Kater SB, Hauser G (1981) Neurite outgrowth in molluscan organ and cell cultures: the role of conditioning factor(s). J Neurosci 1:1008-1021.

Wong RG, Barker DL, Kater SB, Bodnar DA (1984) Nerve growthpromoting factor produced in culture media conditioned by specific CNS tissues of the snail Helisoma. Brain Res 292:81-91.

Zoran MJ, Doyle RT, Haydon PG (1990) Targct-dcpendent induction of secretory capabilities in an identified motoneuron during synaptogenesis. Dev Biol 138:202-213. 